\title{
- Análise da Condutividade Hidráulica Saturada em uma Floresta de Cedro, Madrid, Espanha
}

Rubens Junqueira

Carlos Rogério de Mello

Alisson Souza de Oliveira ${ }^{3}$

Geovane Junqueira Alves 4

Uilson Ricardo Venâncio Aires 5

\section{Resumo}

A condutividade hidráulica saturada do solo $\left(K_{0}\right)$ é de grande importância para a hidrologia, especialmente no contexto da infiltração, em que apresenta grande influência nas condições de geração de escoamento superficial direto, tendo como consequências a formação de inundações, erosão do solo e transporte de sedimentos. Além disso, tem papel fundamental na agricultura, por contribuir para infiltração e disponibilização de água para as plantas e também para conservação do solo e para o meio ambiente. Diante do exposto, o objetivo deste trabalho foi estimar e analisar o comportamento da condutividade hidráulica saturada do solo associada aos seus atributos físicos e declividade e avaliar o escoamento superficial direto, em uma área de floresta de Cedrus deodara, em Madrid, na Espanha. Para tanto, foram realizados testes de infiltração com o método dos anéis concêntricos em três pontos na área de estudo, a fim de obter dados que foram ajustados pelo modelo de Horton para estimar a condutividade hidráulica saturada do solo e também foram realizados testes com um simulador de chuvas a fim de determinar o coeficiente de escoamento superficial. Foram retiradas amostras deformadas do solo para determinação de seus atributos físicos. Os resultados mostraram que o modelo de Horton foi adequado para estimar a condutividade hidráulica saturada do solo. Os valores dos atributos físicos do solo e a declividade influenciaram a condutividade hidráulica saturada do solo. A matéria orgânica associada à declividade do solo proporcionaram os maiores valores de $\mathrm{K}_{0}$. $\mathrm{O}$ escoamento superficial direto apresentou relação inversa à condutividade hidráulica saturada do solo.

Palavras-chave: Infiltração. Simulador de chuvas. Anéis concêntricos. Escoamento superficial direto. Equação de Horton.

\section{Introdução}

A água é um dos elementos primordiais para a vida na Terra e está presente em abundância no planeta, sendo que $70 \%$ de sua superfície está coberta por este recurso. Porém, 97,5\% dessa água

1 Universidade Federal de Lavras, estudante de mestrado em Recursos Hídricos em Sistemas Agrícolas. Lavras, Minas Gerais, Brasil. rubensjunqueira@live.com Rua Capitão Garibaldi, 181, Lavras - MG

2 Universidade Federal de Lavras. UFLA, professor, crmello@deg.ufla.br

3 Unincor, professor, alissonso@hotmail.com

4 Universidade Federal de Lavras, estudante de doutorado em Recursos Hídricos em Sistemas Agrícolas, geovanejunqueira@gmail.com

5 Universidade Federal de Viçosa, estudante de doutorado em Engenharia Agrícola, uvaires@gmail.com 
é salgada, ou seja, imprópria para o consumo humano. Da parcela restante, 68,9\% encontra-se em geleiras, calotas polares ou em regiões montanhosas, 29,9 \% em águas subterrâneas, 0,9 \% armazenada no solo e somente 0,3 \% é considerada como de fácil acesso, presente nos lagos e rios. Outro grande problema em relação à água é sua distribuição espacial: um quarto de toda a água do planeta está na América do Sul, onde se encontra apenas 6 \% da população mundial (BRASIL, 2016).

Na Espanha, há uma grande variabilidade espacial na disponibilidade hídrica: o Norte é singularizado por temperaturas amenas ao longo do ano e alta precipitação, a Região Central é caracterizada por uma alta amplitude térmica, com inverno frio e verão muito quente e seco. Na região sul da Espanha domina o calor durante a maior parte do ano; combinando isso com a baixa pluviosidade faz com que algumas regiões sofram inclusive com a desertificação de parte do seu solo (ESPANHA, 2008). Neste sentido, torna-se fundamental compreender o ciclo da água e sua relação com o solo.

A condutividade hidráulica $(K)$ é uma das propriedades físicas do solo mais importantes na determinação quantitativa e qualitativa do movimento de água no solo e possui grande importância na distribuição de água em seu perfil (MELLO; SILVA, 2013).

A condutividade hidráulica do solo saturado $\left(\mathrm{K}_{0}\right)$ está relacionada com a capacidade de infiltração do solo. Por essa razão, trata-se de um atributo hidrológico de grande importância na modelagem chuva-vazão, dimensionamento de sistemas de irrigação e drenagem, transporte de solutos no solo, recarga de aquíferos, escoamento superficial e transporte de sedimentos (ALVARENGA et al., 2011). Porém, apesar da grande importância, sua determinação é bastante complexa e de alto valor econômico.

De acordo com Mello e Silva (2013), diversos fatores exercem influência sobre a condutividade hidráulica saturada do solo, entre eles pode-se destacar: o relevo, atributos físicos do solo (textura, estrutura, matéria orgânica - MO, entre outros), cobertura vegetal e manejo do solo. Esses fatores combinados fazem com que haja uma grande variabilidade de $\mathrm{K}_{0}$, mesmo em pontos muito próximos geograficamente, o que dificulta ainda mais sua análise (MARTíNEZ, 2016).

Um dos principais problemas envolvidos em sua determinação está relacionado à necessidade de amostras indeformadas, que posteriormente devem ser utilizadas em testes em laboratório, que são dispendiosos e trabalhosos. Esses testes, além de demandar um longo tempo, necessitam também de equipamentos específicos e mão de obra especializada. Uma das alternativas para sua determinação é com a utilização de modelos matemáticos. De acordo com Mello e Silva (2013), o modelo de Horton pode ser utilizado para modelar a capacidade de infiltração do solo e, por meio dela, obter de forma aproximada a condutividade hidráulica saturada do solo.

Diante do exposto, o objetivo deste trabalho foi estimar e analisar o comportamento da condutividade hidráulica saturada do solo em uma Floresta de Cedro, cujo solo predominante é o Cambissolo Eutrófico (Inceptisol, Be) e sua capacidade em gerar escoamento superficial direto, associado aos atributos físicos do solo, areia, silte, argila, teor de matéria orgânica e declividade.

\section{Metodologia}

\section{Localização}

O estudo foi realizado durante os meses de junho e julho de 2016 em uma Floresta de Cedro com área de $2.600 \mathrm{~m}^{2}$, localizada na zona noroeste da cidade de Madrid, Espanha (Figura 1). A área em questão encontra-se na Bacia Hidrográfica do Tejo, com área de 80.100 km², sendo uma das cinco comunidades autônomas da Espanha (CUENCA HIDROGÁFICA DEL TAJO, 201-). Parte da 
bacia está localizada no território de Portugal, sendo considerada uma bacia internacional, as leis que vigoram em um dos países devem estar de acordo com as leis e exigências do outro.

Figura 1. Localização da área de estudo e pontos amostrais.

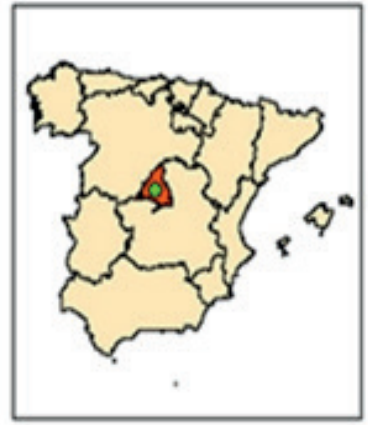

Legenda

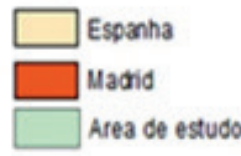

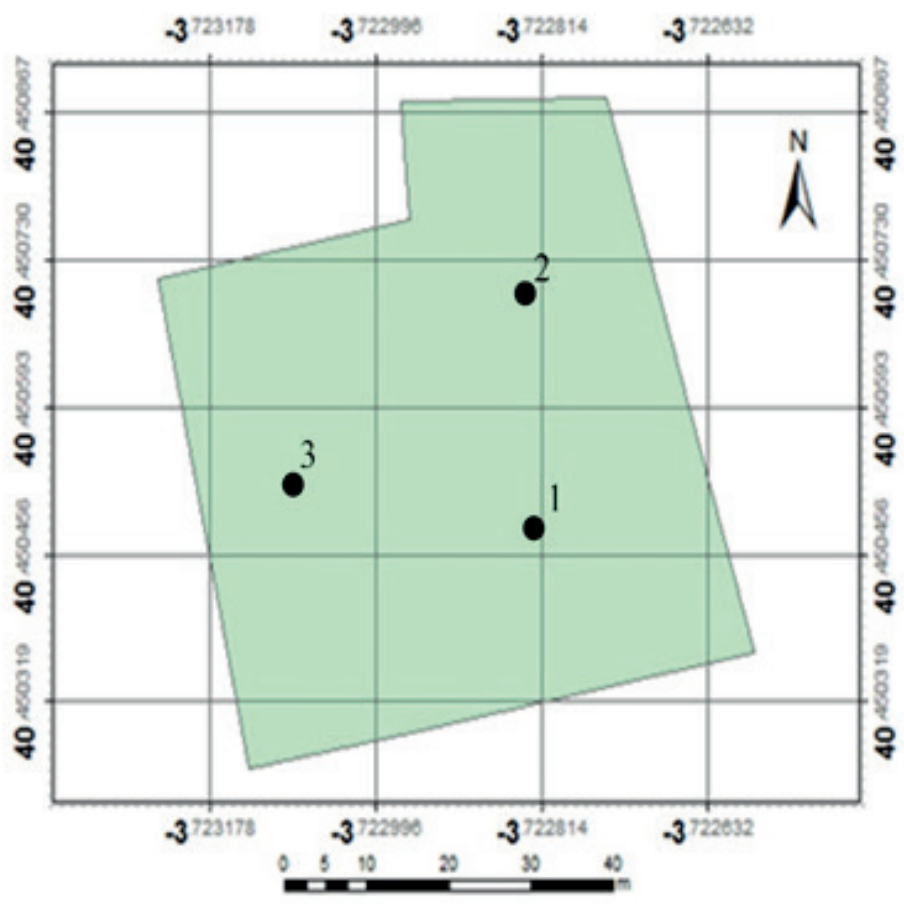

Fonte: Elaboração dos autores (2017).

De acordo com a Agência Estatal de Meteorologia da Espanha (AEMET, 2011) e utilizando a classificação climática de Köppen, o clima da cidade de Madrid é definido como sendo Csa, ou seja, temperado e com verão seco e quente. O período chuvoso se concentra principalmente no inverno, entre os meses de dezembro e março. A média das temperaturas mínima mensal é de $10,1^{\circ} \mathrm{C}$, a máxima chega a $19,9^{\circ} \mathrm{C}$ e a temperatura média anual é de $15^{\circ} \mathrm{C}$. A precipitação total anual gira em torno de $421 \mathrm{~mm}$. Nota-se ainda a presença de neve na cidade, em cerca de 4 dias ao ano, principalmente no período entre novembro e fevereiro.

O tipo de solo presente na região é o Cambissolo Eutrófico (Inceptisol, Be). Os Cambissolos são solos pouco desenvolvidos e, de acordo com a Soil Taxonomy (USDA, 2006), apresentam horizonte intermediário câmbico (horizonte B incipiente - Bi), o qual é um horizonte estrutural ou de alteração, equivalente a horizonte genético Bw (com exceções) ou que apresenta acumulação de óxidos e hidróxidos de ferro, equivalente ao horizonte genético Bs. Ainda de acordo com a USDA, o elemento qualificador êutrico indica saturação por bases maior que $50 \%$.

\section{Atributos físicos do solo}

Para determinação dos atributos físicos do solo (areia, silte, argila e matéria orgânica) foram coletadas amostras deformadas na camada de 0 - $30 \mathrm{~cm}$ em três pontos amostrais, definidos con- 
forme observação em campo. Essas observações foram feitas com base nas posições das plantas, tomando-se cuidado para que os pontos estivessem entre as plantas a uma distância tal que não houvesse interferência das raízes das plantas e tampouco de seus dosséis. Além disso, os pontos foram tomados em posições nas quais as distâncias entre si fossem próximas umas das outras. A localização de cada ponto está disponível na Tabela 1.

Tabela 1. Localização dos pontos de coleta das amostras de solo.

\begin{tabular}{ccc}
\hline \multirow{2}{*}{ Pontos } & \multicolumn{2}{c}{ Localização } \\
\cline { 2 - 3 } & Latitude & Longitude \\
\hline 1 & 40,45048 & $-3,72282$ \\
2 & 40,45070 & $-3,72283$ \\
3 & 40,45052 & $-3,72308$ \\
\hline
\end{tabular}

Fonte: Elaboração dos autores (2017).

Na Figura 2, pode-se visualizar a distribuição dos pontos amostrais na área de estudo.

Figura 2. Contorno da área de estudo e localização dos pontos amostrais.

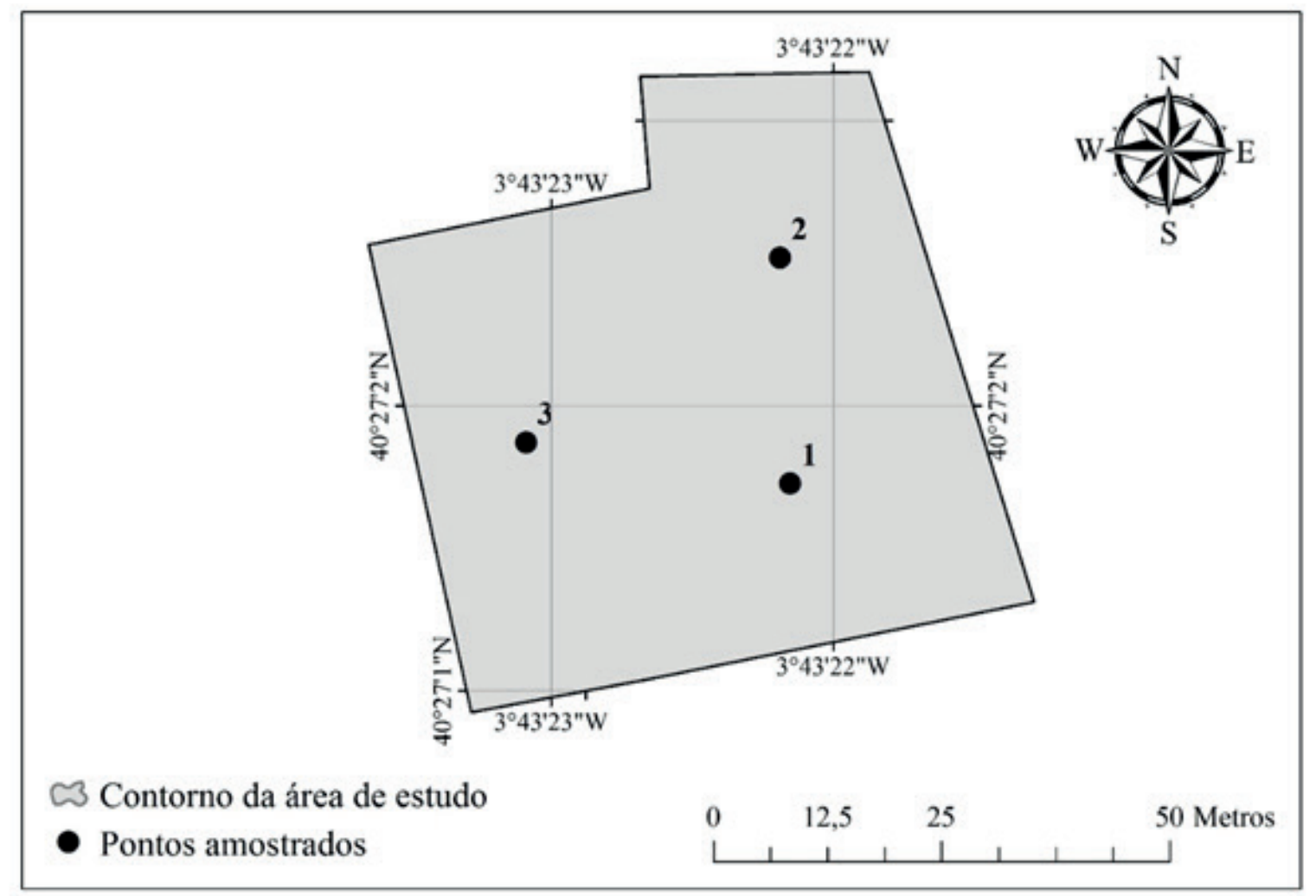

Fonte: Elaboração dos autores (2017).

Em laboratório, foram determinados os atributos físicos do solo, teor de matéria orgânica (MO), porcentagem de terra fina (TF), areia (AR), silte (S) e argila (ARG). 
Para a determinação da porcentagem de terra fina, as amostras foram pesadas e colocadas em bandejas juntamente com água e $\mathrm{NaOH}$. Após 24 horas, as partículas se desagregaram e, com ajuda de uma peneira de $2 \mathrm{~mm}$, foram separadas a terra fina das partículas com diâmetro superior a $2 \mathrm{~mm}$. Essas partículas foram secas ao ar e, posteriormente, pesadas em uma balança de alta precisão. Com isso, foi obtida a quantidade de cascalhos presentes no solo.

Na determinação da textura do solo, foi utilizado o método da pipeta, o qual é conhecido por ser de grande precisão, porém demanda um tempo maior. É um método de sedimentação, que utiliza pipeta para coletar uma alíquota à profundidade e em tempo determinados (FERREIRA et al., 2003).

Após a obtenção das frações granulométricas do solo, foi realizada a classificação textural. Para isso, foi utilizada a classificação elaborada pelos Sistemas de Classificação Norte-Americano (USDA) (Tabela 2).

Tabela 2. Frações granulométricas segundo a classificação do USDA.

\begin{tabular}{cc}
\hline Frações & Diâmetro $(\mathbf{m m})$ \\
\hline Areia muito grossa & $2-1$ \\
Areia grossa & $1-0,5$ \\
Areia média & $0,5-0,25$ \\
Areia fina & $0,25-0,10$ \\
Areia muito fina & $0,10-0,05$ \\
Silte & $0,05-0,002$ \\
Argila & $<0,002$ \\
\hline
\end{tabular}

Fonte: Elaboração dos autores (2017).

Uma vez conhecidas as proporções de areia, silte e argila, foi possível determinar a classe textural do solo, utilizando os diagramas ou triângulos texturais (FERREIRA et al., 2003). Para este trabalho, foi utilizado o triângulo elaborado pela USDA.

A medição da matéria orgânica foi realizada no Laboratório de Geologia e Edafologia, na Escola Técnica Superior de Engenharia de Montanhas, Florestais e Meio Ambiente, que faz parte da Universidade Politécnica de Madrid, sendo que a MO foi obtida por meio de reação de redução-oxidação.

\section{Teste de Infiltração}

Para a realização do teste de infiltração foi empregado o método dos cilindros de anéis concêntricos, cujo teste consiste em medir a infiltração da água no solo utilizando dois anéis, com diâmetros diferentes, cujo centro pertence ao mesmo ponto. A função do anel externo é impedir que a água infiltrada se movimente lateralmente, o que causaria alterações no valor final da infiltração. A medição é realizada no anel central, que possui uma fita métrica em seu interior. 0 anel externo possui diâmetro de $36 \mathrm{~cm}$ e o interno um diâmetro igual a $18 \mathrm{~cm}$, ambos com altura de $18 \mathrm{~cm}$.

O equipamento foi instalado nivelado e cravado ao solo a uma profundidade de aproximadamente metade de sua altura. A superfície onde se realiza o teste deve sofrer o mínimo possível de alterações, para que as condições de infiltração de água no solo sejam as mais próximas da realidade possível.

No primeiro minuto do teste foram realizadas três leituras, uma a cada 20 segundos. Após, realizou-se a leitura a cada 60 segundos. Cada teste foi realizado de tal forma até que ocorresse uma taxa de infiltração constante, ou seja, a lâmina infiltrada deveria ser a mesma para intervalos de tempos iguais. 


\section{Escoamento superficial direto}

Neste estudo foi utilizado o simulador de chuvas fabricado pela empresa holandesa Eijkelkamp Soil \& Water (Figura 3). Este aparelho é bastante utilizado em estudos hidrológicos e em projetos de irrigação devido a sua maior proximidade à realidade. 0 esquema a seguir ilustra como o simulador deve ser instalado em campo:

Figura 3. Esquema de montagem do simulador de chuvas.
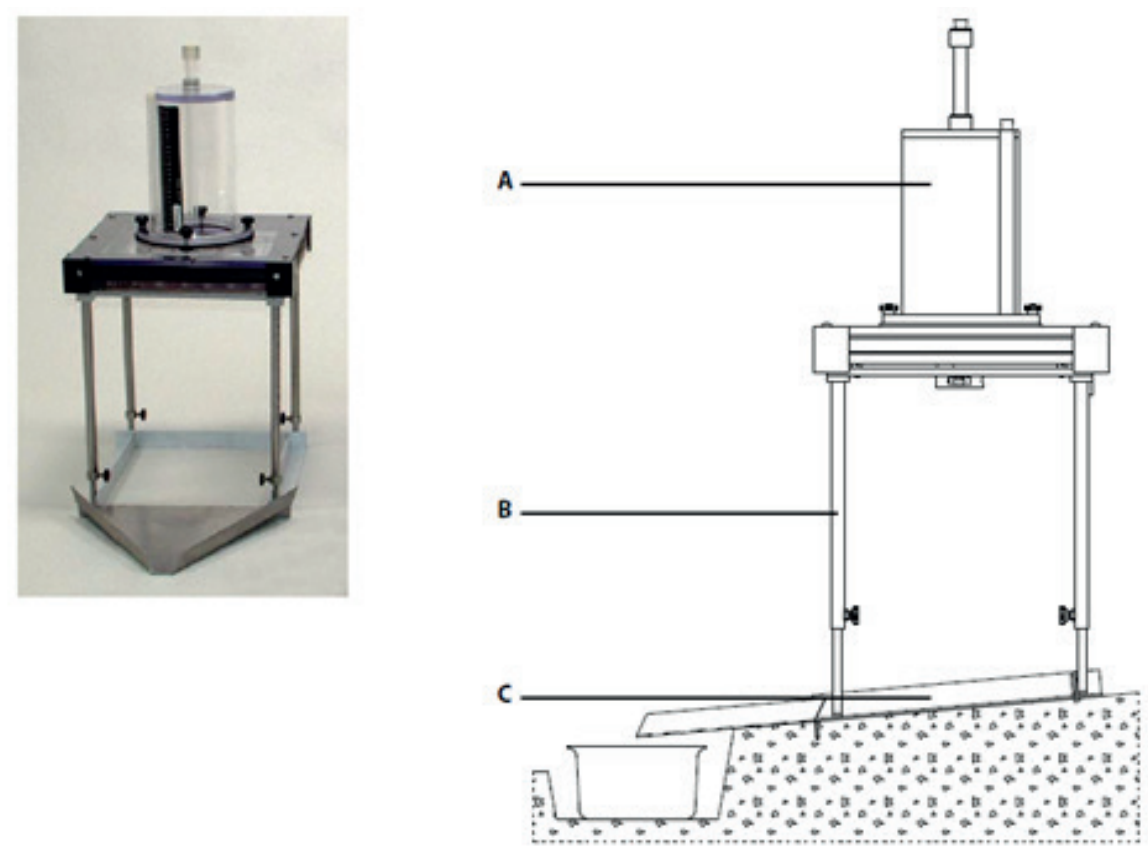

Fonte: Eijkelkamp Soil \& Water (201-).

Conforme observado na imagem, o simulador de chuvas é composto por três partes essenciais: a primeira é um aspersor $(A)$ com um regulador de pressão embutido para a produção da chuva padrão. A segunda parte é composta por um suporte ajustável (B) para o aspersor, o qual deve estar nivelado. $\mathrm{O}$ ajuste de nível é realizado em suas quatro pernas de aço inoxidável, cada uma possuindo uma borboleta que permite realizar o nivelamento de forma individual. Além disso, um nível na parte superior ajuda a encontrar o melhor posicionamento. A terceira parte trata-se de uma moldura de aço inoxidável (C), que é fixado sobre o solo, com o auxílio de quatro grandes pregos, e impede o movimento lateral da água. Uma calha é instalada na mesma linha do solo e é utilizada para conduzir a água e sedimento para um recipiente de coleta.

Um dos componentes mais importantes e mais complexos desse aparelho é o aspersor, o qual pode ser visto com mais detalhes na Figura 4. 
Figura 4. Aspersor e seus componentes.

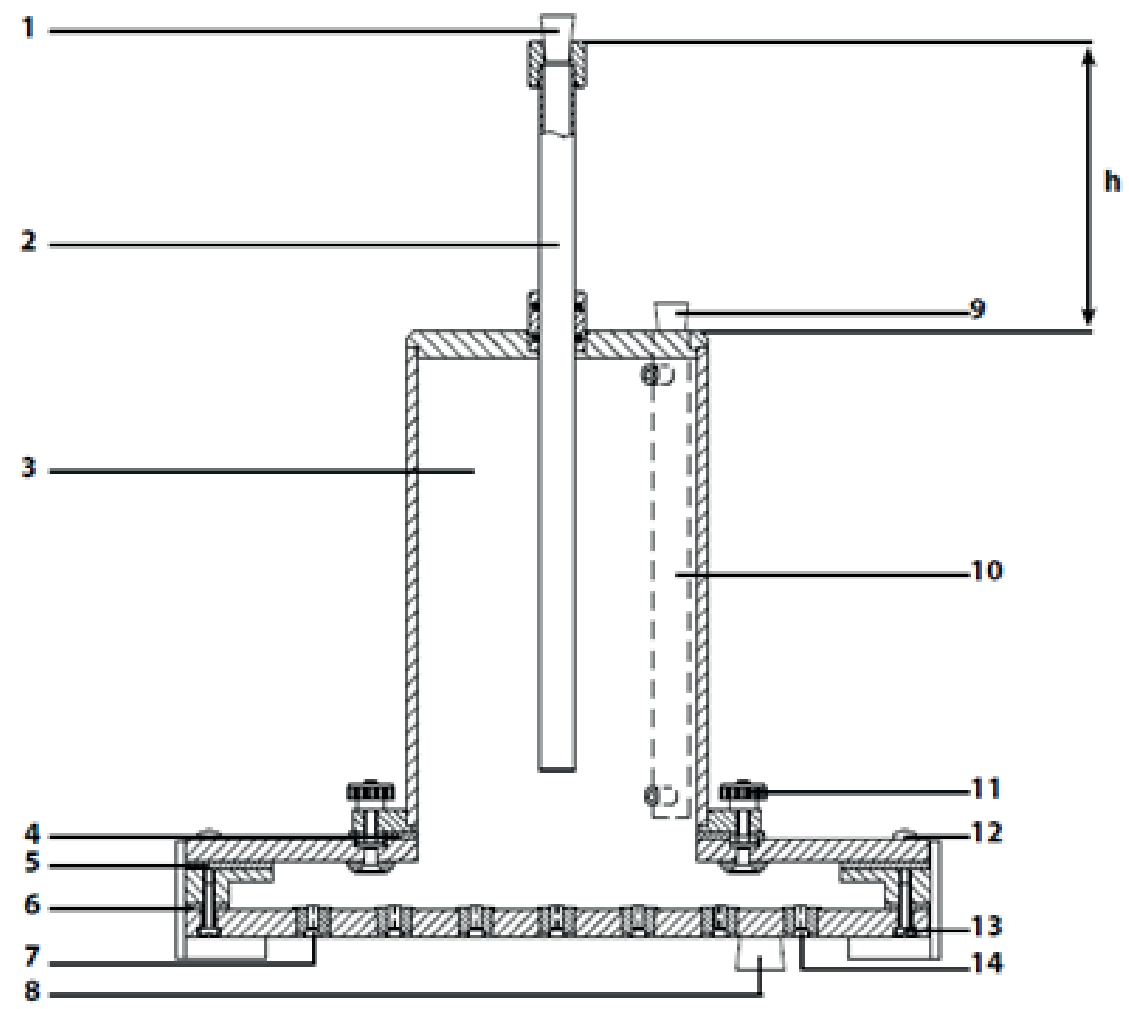

Fonte: Eijkelkamp Soil \& Water (201-).

O aspersor é formado por um reservatório cilíndrico calibrado (3), com uma capacidade de aproximadamente $2.300 \mathrm{~mL}$, o qual está conectado à cabeça de aspersão. 0 nível d'água pode ser lido no tubo de leitura (10), o qual é fechado por uma tampa (9). A água é liberada através de 49 aspersores (14), igualmente espaçados. A pressão e o diâmetro interior dos aspersores determinam a vazão do aparelho. Essa pressão pode ser alterada subindo ou descendo o tubo de arejamento (2). Para se colocar água dentro do aspersor deve-se colocá-lo virado para baixo e, através da abertura de enchimento, que geralmente está fechada com um tampão (8), colocar a água, após isso deve-se fechar novamente com o tampão e virar o aspersor.

Para conseguir a intensidade de chuva de $6 \mathrm{~mm} / \mathrm{min}$ foi preciso ajustar o tubo de arejamento (h) com $12 \mathrm{~cm}$ de distância entre o reservatório e a parte superior do tubo. Com isso, a intensidade de aplicação foi de aproximadamente $375 \mathrm{~mL} / \mathrm{min}$. Cada teste foi realizado quatro vezes, totalizando 20 minutos, sendo que a cada vez que se enchia o aspersor, realizava-se a leitura de escoamento superficial, utilizando provetas graduadas. As leituras eram realizadas a cada minuto, sendo que no primeiro minuto de cada teste foram realizadas leituras a cada 20 segundos. 
Figura 5. Simulador de chuvas em funcionamento em campo.

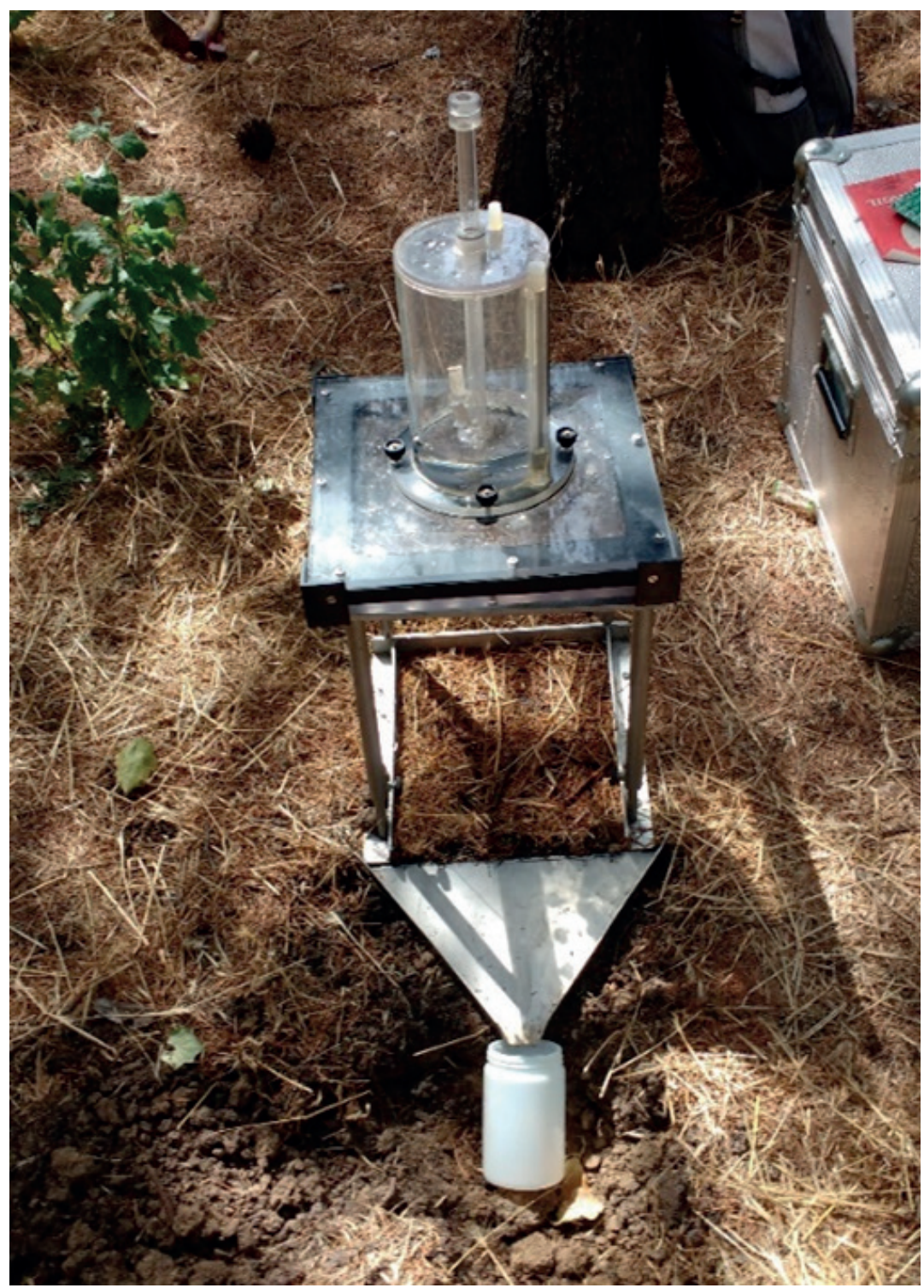

Fonte: Elaboração dos autores (2016).

Após a realização dos testes com o aparelho, foi realizado o cálculo do coeficiente de escoamento superficial, que é resultado do volume de água escoado sobre o solo em relação ao total de água precipitada.

\section{Resultados e discussão}

\section{Condutividade hidráulica}

Os resultados do ajuste do modelo de Horton aos dados do teste de infiltração podem ser visualizados na Figura 6. 
Figura 6. Infiltração acumulada nos três pontos amostrados.

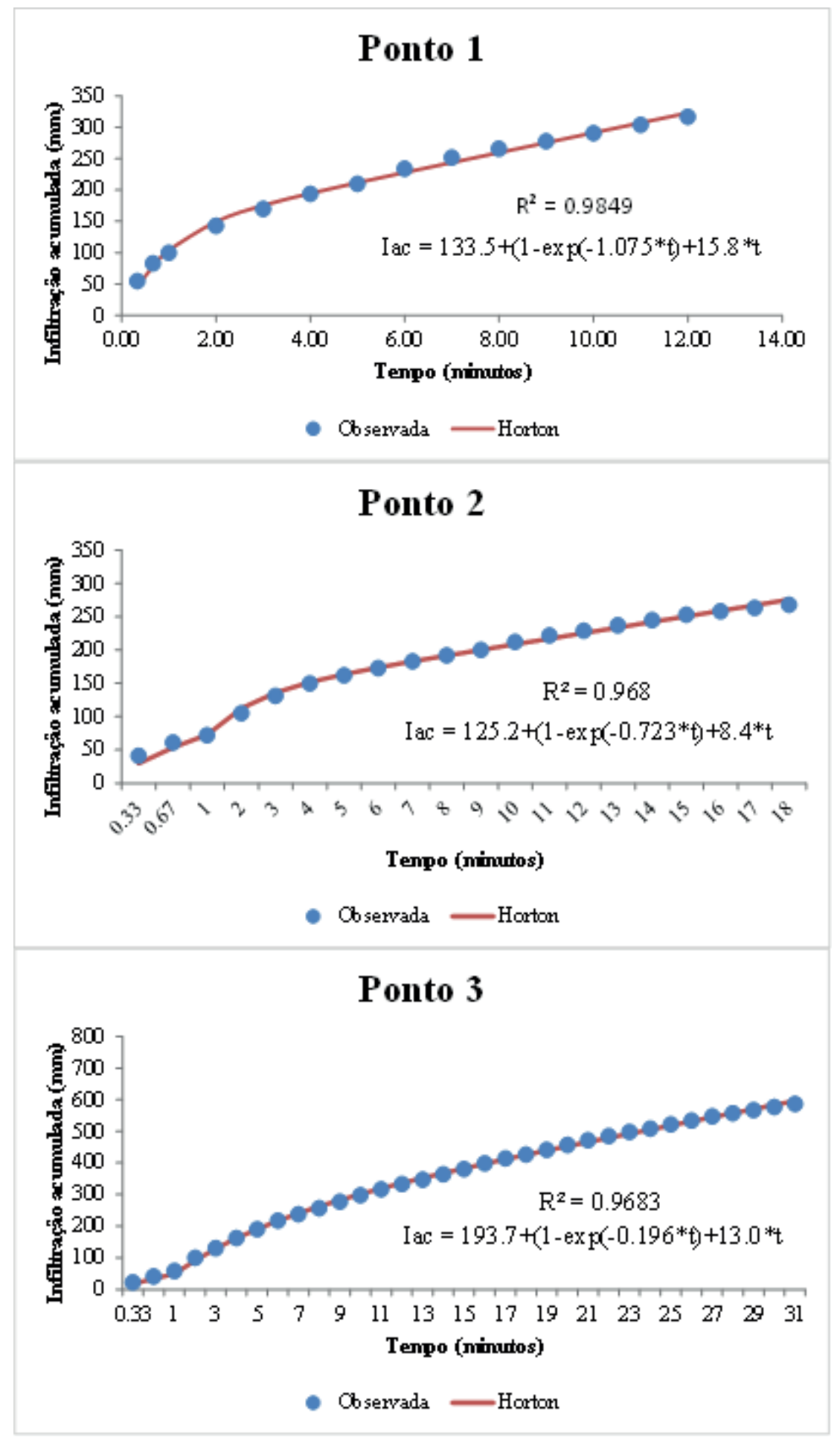

Fonte: Elaboração dos autores (2017).

É possível perceber que o modelo de Horton proporcionou um bom ajuste aos dados, visto que em todos os pontos apresentou coeficiente de determinação $\left(R^{2}\right)$ acima de $96 \%$, o que demonstra a adequabilidade desse modelo para a curva de infiltração acumulada. 
A partir dos dados de infiltração acumulada, obtiveram-se as curvas de capacidade de infiltração, que podem ser visualizadas na Figura 7.

Figura 7. Curvas de capacidade de infiltração de água no solo ajustada pelo modelo de Horton.

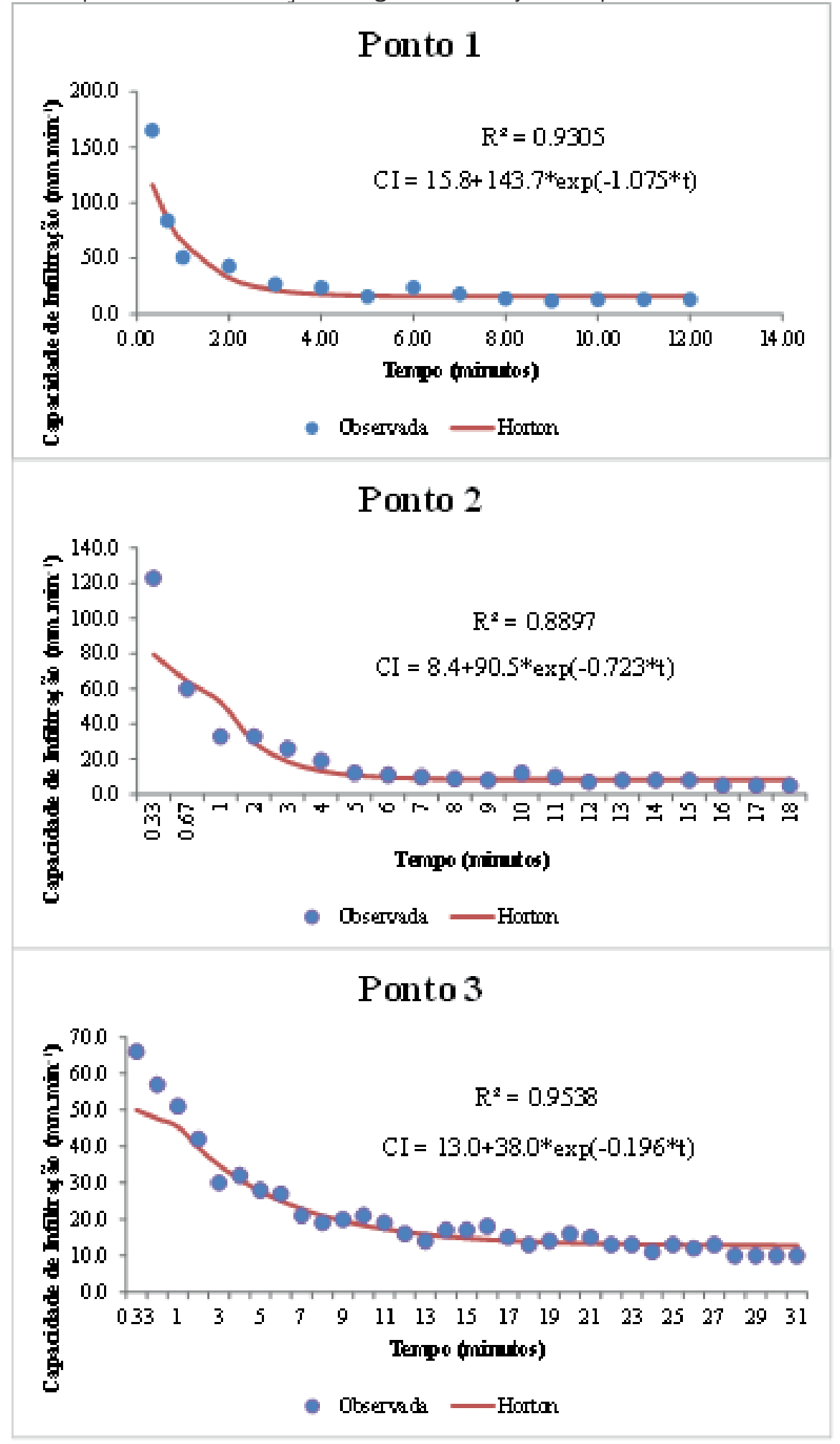

Fonte: Elaboração dos autores (2017). 
O modelo de Horton subestimou a capacidade de infiltração na fase inicial, conforme também relataram Sobrinho et al. (2003), Tomasini et al. (2010) e Santos et al. (2016) em seus trabalhos. Contudo, conseguiu modelar de maneira satisfatória o restante da curva, o que pode ser comprovado pelo coeficiente de determinação $\left(R^{2}\right)$ superior a $89 \%$.

Ainda de acordo com Santos et al. (2016), em trabalho realizado em um Argissolo Vermelho Amarelo, o Modelo de Horton foi o que obteve melhor ajuste da capacidade de infiltração, quando comparado aos modelos de Kostiakov, Kostiakov-Lewis e Philip, com valores muito próximos aos obtidos em campo.

Na Tabela 4 estão apresentados os valores de condutividade hidráulica saturada do solo estimadas com base no Modelo de Horton.

Tabela 4. Condutividade hidráulica saturada do solo com base no Modelo de Horton.

\begin{tabular}{cc}
\hline Ponto & Condutividade hidráulica saturada $\left(\mathbf{c m} \cdot \mathbf{h}^{-1}\right)$ \\
\hline 1 & 94,7 \\
2 & 50,1 \\
3 & 76,2 \\
\hline
\end{tabular}

Fonte: Elaboração dos autores (2017).

Segundo o Sistema Brasileiro de Classificação de Terras para Irrigação (2011), elaborado pela Embrapa Solos/CODEVASF, todos os pontos possuem condutividade hidráulica muito rápida (maior que $12 \mathrm{~cm} \cdot \mathrm{h}^{-1}$ ).

Os valores de condutividade hidráulica saturada podem ser explicados com base nos atributos físicos do solo e declividade na área de estudo (Tabela 5).

Tabela 5. Atributos físicos do solo, areia, silte, argila, matéria orgânica e declividade.

\begin{tabular}{ccccccc}
\hline Pontos & \% Areia & \% Silte & \% Argila & Classe Textural & MO (\%) & Declividade (\%) \\
\hline 1 & 50,5 & 30,5 & 19,0 & Franca & 2,92 & 7,27 \\
2 & 58,0 & 25,0 & 17,0 & Franca-arenosa & 1,82 & 22,18 \\
3 & 57,0 & 27,0 & 16,0 & Franca-arenosa & 1,85 & 9,09 \\
\hline
\end{tabular}

Fonte: Elaboração dos autores (2017).

Segundo Carvalho (2002), a textura é uma das características mais importantes entre os atributos do solo que causam interferência na condutividade hidráulica, devido à sua grande correlação com outros atributos ou com fenômenos que ocorrem no solo.

$\mathrm{O}$ ponto 1 foi o que apresentou maior valor de $\mathrm{K}_{0}$, devido aos altos valores de matéria orgânica e de silte, embora apresente menor teor de areia e maior teor de argila. Os maiores teores de MO corroboram para um solo mais bem estruturado que contribuiu para o processo de infiltração e, consequentemente, maior valor de $\mathrm{K}_{0}$. $\mathrm{O}$ ponto 3, apesar de possuir valores de matéria orgânica ligeiramente superior aos do ponto 2 e mesma classe textural, foi o que apresentou o segundo maior valor de condutividade hidráulica. Por fim, o ponto 2 apresentou menor condutividade hidráulica devido ao seu menor teor de matéria orgânica. 
O teor de matéria orgânica no solo é considerado moderado para a região. A distribuição de MO é desigual ao longo do solo, podendo chegar a uma variação de mais de $60 \%$, comparando o ponto 1 em relação ao ponto 2 . Essa variação pode estar relacionada ao teor de argila, o qual é responsável pela maior humificação (enriquecimento de matéria orgânica), que é maior no ponto 1. A matéria orgânica possui relação direta com a condutividade hidráulica saturada do solo, o que pode estar relacionado ao fato de que o teor de MO favorece a diminuição da densidade do solo pela sua maior estruturação (ASSIS; LANÇAS, 2005).

A declividade do solo apresentou relação inversa com a condutividade hidráulica saturada do solo, ou seja, a água tende a se movimentar com maior facilidade em terrenos mais planos. Em trabalho realizado em Cordoba, região sul da Espanha, Polo, Lafuente e Giráçdez (2003) encontraram valores de condutividade hidráulica saturada muito superiores nas regiões planas, quando comparadas a regiões com maiores declividades.

Alvarenga et al. (2011) relataram em trabalho realizado em solo Cambissolo a alta variabilidade espacial da condutividade hidráulica saturada do solo a pequenas distâncias, principalmente quando associada às inúmeras combinações de classes, relevo, ocupação e manejo do solo. Em trabalho semelhante realizado no estado da Bahia, Fontana et al. (2016) demonstraram a alta variabilidade de $\mathrm{K}_{0}$ não só a pequenas distâncias, como também a diferentes profundidades.

\section{Escoamento superficial direto}

O escoamento superficial direto foi avaliado com base no coeficiente de escoamento. Na Tabela 6 podem-se visualizar os valores do coeficiente de escoamento superficial obtido para os três pontos estudados.

Tabela 6. Coeficiente de escoamento superficial direto para os pontos estudados.

\begin{tabular}{cc}
\hline Pontos & Coef. escoamento superficial (\%) \\
\hline 1 & 1,13 \\
2 & 26,76 \\
3 & 3,26 \\
\hline
\end{tabular}

Fonte: Elaboração dos autores (2017).

Quando se analisa o coeficiente de escoamento, fica evidente a relação inversa à condutividade hidráulica saturada, ou seja, o ponto 1 que apresentou o maior valor de $K_{0}(94,7 \mathrm{~cm}$.h-1) foi o que apresentou o menor coeficiente de escoamento $(1,13 \%)$, seguido do ponto 3 (segundo maior valor de $\left.\mathrm{K}_{0} 76,2 \mathrm{~cm} \cdot \mathrm{h}^{-1}\right)$ apresentando o segundo menor valor do coeficiente de escoamento $(3,26 \%)$. Finalmente, o ponto 2 que apresentou o menor valor de $K_{0}\left(50,1 \mathrm{~cm} . \mathrm{h}^{-1}\right)$ foi o que apresentou o maior valor de coeficiente de escoamento. Fica evidente a relação inversa entre a condutividade hidráulica saturada e o escoamento superficial direto, o que confirma a capacidade do Modelo de Horton em estimar a condutividade hidráulica saturada do solo.

Os valores do coeficiente de escoamento superficial direto são justificados pelos valores dos atributos físicos do solo e declividade. 


\section{Conclusões}

O Modelo Horton mostrou-se adequado para estimar a condutividade hidráulica saturada do solo.

A condutividade hidráulica saturada, associada ao Cambissolo Eutrófico, em uma floresta de cedro apresentou valores entre 50 e $95 \mathrm{~cm} \cdot \mathrm{h}^{-1}$

O coeficiente de escoamento superficial direto variou de 1 a $27 \%$.

\section{Analysis of Saturated Hydraulic Conductivity in a Cedar Forest, Madrid, Spain}

\section{Abstract}

Soil saturated hydraulic conductivity $\left(\mathrm{K}_{0}\right)$ is of great importance for hydrology, especially for the soil water infiltration process, since it influences considerably the conditions of direct runoff generation, causing floods, soil erosion and transportation of sediments. In addition, it plays a fundamental role in agriculture, as it contributes to the infiltration and availability of water for plants and to soil and environment preservation. Therefore, the aim of this work was to estimate and analyze the behavior of soil saturated hydraulic conductivity, associated to soil physical attributes and site slope, besides evaluating the direct runoff in a forest site of Cedrus deodara, in Madrid, Spain. We performed soil infiltration test using concentric rings in three points of the study area in order to obtain data, which was adjusted by the Horton Model to estimate soil stable water infiltration $\left(\mathrm{K}_{0}\right)$. A rainfall simulation test to determine the direct runoff coefficient was also carried out. In order to set soil physical attributes, we collected deformed soil samples from the site. The results showed the Horton model is adequate to estimate $\mathrm{K}_{0}$; the values of soil physical attributes and site slope have influenced $\mathrm{K}_{0}$; the organic matter associated to site slope provided the highest values for $\mathrm{K}_{0}$, and the direct runoff presented an inverse relation to $\mathrm{K}_{0}$.

Keywords: Water Infiltration. Rainfall simulator. Concentric rings. Direct runoff. Horton Model.

\section{Referências}

AGENCIA ESTATAL DE METEOROLOGIA - AEMET (Espanha). Atlas Climatológico Ibérico. 2011. Disponível em: <http://www.aemet.es/documentos/es/conocermas/recursos_en_linea/ publicaciones_y_estudios/publicaciones/Atlas-climatologico/Atlas.pdf>. Acesso em: 19 set. 2016.

ALVARENGA, C. C.; MELLO, C. R.; MelLO, J. M.; VIOLA, M. R. Continuidade espacial da condutividade hidráulica saturada do solo na Bacia Hidrográfica do Alto Rio Grande, MG. Revista Brasileira de Ciência do Solo, v. 35, n. 5, p. 1745-1757, 2011. Disponível em: <http://www. redalyc.org/html/1802/180221126029/>. Acesso em: 19 dez. 2016.

ALVES SOBRINHO, T.; VITORINO, A. C. T.; SOUZA, L. C. F. de; GONÇALVES, M. C.; CARVALHO, D. F. de. Infiltração de água no solo em sistemas de plantio direto e convencional. Revista Brasileira de Engenharia Agrícola e Ambiental, v. 7, n. 2, p. 191-196. 2003. 
ASSIS, R. L.; LANÇAS, K. P. Avaliação dos atributos físicos de um Nitossolo Vermelho distroférrico sob sistema plantio direto, preparo convencional e mata nativa. Revista Brasileira de Ciência do Solo, p. 515-522, 2005. Disponível em: < http://www.scielo.br/pdf/\%0D/rbcs/v29n4/26100.pdf>. Acesso em: 13 dez. 2016.

BRASIL. Ministériodo MeioAmbiente. Água, um recursocadavezmaisameaçado. Disponívelem: < http:// www.mma.gov.br/estruturas/sedr_proecotur/_publicacao/140_publicacao09062009025910.pdf>. Acesso em: 19 set. 2016. 2016.

CARVALHO, L. A. Condutividade hidráulica do solo no campo: as simplificações do método do perfil instantâneo. Data de defesa: 23 jan. 2013. 98 f. Tese de Doutorado. Universidade de São Paulo. 2002.

CUENCA HIDROGRÁFICA DEL TAJO. Ámbito Territorial. Disponível em: <http://www.chtajo.es/ DemarcaTajo/AmbitoTerritorial/Paginas/default.aspx>. Acesso em: 19 set. 2016. 201 ?

ESPANHA. Ministério de Agricultura, Alimentación y Medio Ambiente. Programa de Acción Nacional Contra la Desertificación. Disponível em: <http://www.magrama.gob.es/es/desarrollorural/temas/ politicaforestal/Resumen_PAND_agosto_2008_tcm7-19665.pdf > Acesso em: 28 set. 2016. 2008.

FERREIRA, M. M.; DIAS JÚNIOR, M. S.; MESQUITA, M. G. B. F.; ALVES, E. A. B. F. Física do Solo, Textura. Lavras: Editora UFLA, 2003. cap. 2 p 7-17. (Texto Acadêmico).

FONTANA, A.; TEIXEIRA, W. G.; BAlieIRO, F. D. C.; MOURA, T. P. A. D.; MENEZES, A. R. D.; SANTANA, C. I. Characteristics and attributes of Oxisols under different land uses in the western region of the state of Bahia, Brazil. Pesquisa Agropecuária Brasileira, n. 51, v. 9, 1457-1465. 2016.

MARTínEZ, C. M. Projeto e Construção de um Permeâmetro de Parede Flexível e Carga Constante. 2016. 114 f. Dissertação (Mestrado) - Universidade de Brasília, Brasília, 2016.

MELLO, C. R.; SILVA, A. M. Hidrologia: princípios e aplicações em sistemas agrícolas. Hidrologia do Solo. Lavras: UFLA, Editora UFLA, 2013. cap. 6 p. 291-342.

POLO, M. J.; LAFUENTE, P.; GIRÁÇDEZ, J. V. Variabilidad espacial de la conductividad hidráulica saturada en suelos de olivar y su influencia en el balance hidrológico global. Estudios de la zona no saturada del suelo. v. 6, p. 209-213. 2003.

SANTOS, I. L. N.; GOMES FILHO, R. R.; CARVALHO, C. M.; SANTOS, K. V.; OLIVEIRA, D. T. B.; SOUZA, L. G. Velocidade de infiltração da água no solo cultivado por milho doce com cobertura de Crotalária. 2016. Revista Brasileira de Agricultura Irrigada, v. 10, n. 5, 925-934. 2016. Disponível em: < https://www.researchgate.net/profile/Clayton_Carvalho/publication/309643210_VELOCIDVEL_ DE_INFILTRACAO_DA_AGUA_NO_SOLO_CULTIVADO_POR_MILHO_DOCD_COM_COBERTURA_DE_ CROTALARIA/links/581b4cb408aea429b28fcOf1/VELOCIVELO-DE-INFILTRACAO-DA-AGUA-NOSOLO-CULTIVADO-POR-MILHO-DOCE-COM-COBERTURA-DE-CROTALARIA.pdf>. Acesso em: 18 dez. 2016.

SOIL SURVEY STAFF. Keys of soil taxonomy. Tenth Edition. Washington, DC: USDA-NCRS, 2006. 
TOMASINI, B. A.; VITORINO, A. C. T.; GARBIATE, M. V SOUZA, C. M. A.; 4, TEODORICO A. T. S. Infiltração de água no solo em áreas cultivadas com cana-de-açúcar sob diferentes sistemas de colheita e modelos de ajustes de equações de infiltração. Engenharia Agrícola, v. 30, n. 6, p. 1060 1070. 2010. Disponível em: < http://www.scielo.br/scielo.php?script=sci_arttext\&pid=S010069162010000600007\&lng=pt\&tlng=pt>. Acesso em: 17 nov. 2016.

\section{Histórico editorial:}

Submetido em: 13/03/2017

Aceito em: 27/07/2017

\section{Como citar:}

ABNT

JUNQUEIRA, R.; MELLO, C. R. de; OLIVEIRA, A. S. de; ALVES, G. J.; AIRES, U. R. V. Análise da Condutividade Hidráulica Saturada em uma Floresta de Cedro, Madrid, Espanha. Revista Agrogeoambiental, Pouso Alegre, v. 10, n. 3, p. 75-89, jul./set. DOI: http://dx.doi.org/10.18406/2316-1817v10n320181185

\section{$\underline{A P A}$}

JUNQUEIRA, R., MELLO, C. R. de, OLIVEIRA, A. S. de, ALVES, G. J. \& AIRES, U. R. V. (2018). Análise da Condutividade Hidráulica Saturada em uma Floresta de Cedro, Madrid, Espanha. Revista Agrogeoambiental, 10 (3), 75-89. DOI: http://dx.doi.org/10.18406/2316-1817v10n320181185

$\underline{I S O}$ JUNQUEIRA, R.; MELLO, C. R. de; OLIVEIRA, A. S. de; ALVES, G. J. e AIRES, U. R. V. Análise da Condutividade Hidráulica Saturada em uma Floresta de Cedro, Madrid, Espanha. Revista Agrogeoambiental, 2018, vol. 10, n. 3, pp. 75-89. Eissn 2316-1817. DOI: http://dx.doi.org/10.18406/2316-1817v10n320181185

\section{VANCOUVER}

Junqueira R, Mello CR de, Oliveira AS de, Alves GJ, Aires URV. Análise da Condutividade Hidráulica Saturada em uma Floresta de Cedro, Madrid, Espanha. Rev agrogeoambiental. 2018. jul./set.; 10(3): 75-89.

DOI: http://dx.doi.org/10.18406/2316-1817v10n320181185 


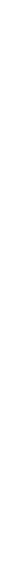

